\title{
Genetic Characterization of Indian mustard (Brassica juncea L.) Germplasm for Quantitative Traits through Principal Component Analysis
}

\author{
Neelam Shekhawat* and Kartar Singh \\ ICAR-National Bureau of Plant Genetic Resources, Regional Station, \\ Jodhpur (Rajasthan)-342005, India \\ *Corresponding author
}

\section{Keywords}

Indian mustard, Multivariate analysis, Principal Component analysis

Article Info

Accepted:

10 April 2020

Available Online:

10 May 2020

\section{A B S T R A C T}

Information on the extent of genetic variability among agronomically important traits is a prerequisite to plan an appropriate plant breeding method. Thirty-five Indian mustard germplasm accessions from ICAR-NBPGR, RS, Jodhpur were evaluated for 11 quantitative characters for determining the pattern of variation, relationship among individuals and their characteristics. Principal component analysis was used to know the variation and to estimate the relative contribution of various traits towards total variability. Results showed that there are five axes which accounted for $74.87 \%$ cumulative variance of the total variability for eleven agro-morphological traits. PC1 exhibited $25.32 \%$ of the total variability contributed by the traits like days to $50 \%$ flowering, days to maturity, plant height and siliqua length. PC2 showed $18.71 \%$ of the total variation and the traits viz., number of secondary branches, number of siliqua per plant, test weight and seed yield per plant contribute to the variation. PC 3 had the contribution from the characters like number of primary branches per plant, length of main branch and number of seeds per siliqua which contributed $13.63 \%$ of the total variation. Days to $50 \%$ maturity, number of secondary branches per plant, number of siliqua per plant and test weight had contributed $8.91 \%$ of the total variation in PC4. PC5 exhibited $8.30 \%$ of the total variability. Thus, the results revealed vast genetic variability exists in the germplasm accessions which may be useful as source for variable characters in Indian mustard improvement.

\section{Introduction}

Indian mustard [Brassica juncea (L) Czern\&Coss] is an important oilseed crop of Brassicaceae family which accounts more than $70 \%$ under rapeseed and mustard. The Brassicaceae, contains about 3500 species and 350 genera, is one of the 10 most economically important plant families. Rapeseed-mustard comprising eight different species viz. Indian mustard, toria, yellow sarson, brown sarson, gobhisarson, karanrai, black mustard and taramira are being cultivated in 53 countries spreading all over the world. Indian mustard (Brassica juncea L.) is the second most important oilseed crop 
of the world as well as India. In India, mustard and rape seed are being grown largely in states like Uttar Pradesh, Rajasthan, Haryana, Assam, Gujarat, Punjab, West Bengal and Madhya Pradesh. Indian mustard is a natural amphidiploid $(2 \mathrm{n}=36)$ of Brassica campestris $(2 \mathrm{n}=20)$ and Brassica nigra $(2 \mathrm{n}=16)$. It is self-compatible and largely selfpollinated crop (85-90\%).

Mustard is a Rabi season crop of temperate region, which requires relatively cool temperature. This crop prefers moderate temperature during growth i.e. below $28^{\circ} \mathrm{C}$ day temperature and it is resistant to frost at all the growth stages. It is grown on a wide range of soil types from fairly heavy clay to light sandy soil. Mustard seed is largely crushed for oil, which is perhaps the cheapest source of oil in our daily diet. Mustard seeds contain about 38-42\% oil, which is golden yellow, fragrant and considered among the healthiest and most nutritional cooking medium. In addition to this, it is also utilized as condiment, for medicinal uses and in preparation of soaps, hair oil, lubricants, paints, plasticizers and as a condiment in pickles.

The extent of diversity available any crop decides the success of any crop improvement programme with manifested objectives. Assemblage and assessment of divergence in the mustard germplasm is essential to know the spectrum of diversity as many such studies have been conducted across the India. In the present investigation, 35 germplasm accessions of Indian mustard were studied for the assessment of genetic diversity by multivariate analysis.

\section{Materials and Methods}

This experiment consisted of 35 national elite germplasm accessions of Indian mustard including 3 checks conserved in Medium
Term Storage, NBPGR, RS, Jodhpur. The trial was laid out in a randomized block design with three replications during Rabi2019 at Research field of NBPGR, Regional Station, Jodhpur, India situated at about $28^{0} 35^{\prime} \mathrm{N}$, longitude of $70^{\circ} 18^{\prime} \mathrm{E}$ and an altitude of $227 \mathrm{~m}$ above mean sea level. The observations for 11 morphological traits were recorded on five randomly selected plants of each accession as per the standard descriptors by NBPGR.

The 11 traits are as follows: days to $50 \%$ flowering, days to maturity, plant height, number of primary branches per plant, number of secondary branches per plant, length of main branch, number of silique per plant, length of silique, number of seeds per silique, 1000 seed weight and seed yield per plant. The data were subjected to PCA was performed using the statistical package $\mathrm{R}$ 3.6.1 version. Principal component analyses (PCA) based on 11 quantitative traits was carried out to find the relative importance of different traits in capturing the variation in germplasm.

\section{Results and Discussion}

PCA is a powerful technique in genetic diversity studies for data reduction. PCA removes interrelationships among components and identify variables which contribute most to genetic variability to be selected for further characterizing genotypes. In present investigation data collected on the quantitative characters were analyzed for principal component analysis using $R$ software.

The PCA produced eigenvalues and factor scores that were used respectively to measure the relative discriminative power of the axes and their associated characters. The result of the PCA showed that four of the 5 principal component axes had eigenvalues greater than 
one and altogether accounted for $74.87 \%$ of the total variation among 35 accessions evaluated for eleven different agromorphological traits. The traits in first component (PC1) contributing in a positive direction are number of primary branches per plant, length of main branch, number of silique per plant, number of seeds per silique, 1000 seed weight and seeds yield per plant.

These are the major characters of plant morphological and seed yield contributing traits contributed maximum 25.32 per cent variability to the first principal component (PC 1) (Table 1, Fig. 1) indicating that the high yielding lines were differentiated on the basis of these characters.

Similar trend using PC analysis in Indian mustard for the traits seed yield per plant, number of primary branches per plant and plant height was reported by Belete et al., (2011), Ray et al., (2014) and Neeru et al., (2015).

Table.1 Eigen value and percent of total variation for various principal components

\begin{tabular}{|c|c|c|c|}
\hline Components & Eigen value & Variance explained (\%) & Cumulative (\%) \\
\hline PC1 & 2.794 & 25.32 & 25.32 \\
\hline PC2 & 2.308 & 18.71 & 44.03 \\
\hline PC3 & 1.592 & 13.63 & 57.66 \\
\hline PC4 & 1.093 & 8.91 & 66.57 \\
\hline PC5 & 1.012 & 8.30 & 74.87 \\
\hline
\end{tabular}

Table.2 Factor loadings of eleven characters with respect to different PC's (Principal components)

\begin{tabular}{|l|l|l|l|l|l|}
\hline \multicolumn{1}{|c|}{ Characters } & \multicolumn{1}{|c|}{$\mathbf{1}$} & $\mathbf{2}$ & $\mathbf{3}$ & $\mathbf{4}$ & $\mathbf{5}$ \\
\hline Days to 50 \% flowering & -0.745 & 0.061 & 0.135 & 0.027 & 0.082 \\
\hline Days to maturity & -0.555 & 0.177 & -0.378 & 0.486 & -0.119 \\
\hline Plant height & -0.616 & 0.469 & -0.047 & 0.214 & 0.222 \\
\hline $\begin{array}{l}\text { Number of primary branches } \\
\text { per plant }\end{array}$ & 0.545 & -0.208 & -0.601 & 0.076 & 0.223 \\
\hline $\begin{array}{l}\text { Number of secondary branches } \\
\text { per plant }\end{array}$ & -0.077 & 0.573 & -0.227 & -0.597 & 0.208 \\
\hline Length of main branch & 0.560 & 0.560 & -0.200 & -0.114 & 0.449 \\
\hline Number of siliqua per plant & 0.377 & 0.673 & 0.0455 & 0.414 & 0.235 \\
\hline Length of siliqua & -0.302 & 0.084 & 0.588 & -0.102 & 0.541 \\
\hline Number of seeds per siliqua & 0.527 & -0.254 & 0.633 & 0.171 & -0.067 \\
\hline 1000 seed weight & 0.122 & 0.682 & 0.094 & -0.336 & -0.478 \\
\hline Seed yield per plant & 0.616 & 0.661 & 0.159 & 0.262 & -0.092 \\
\hline
\end{tabular}




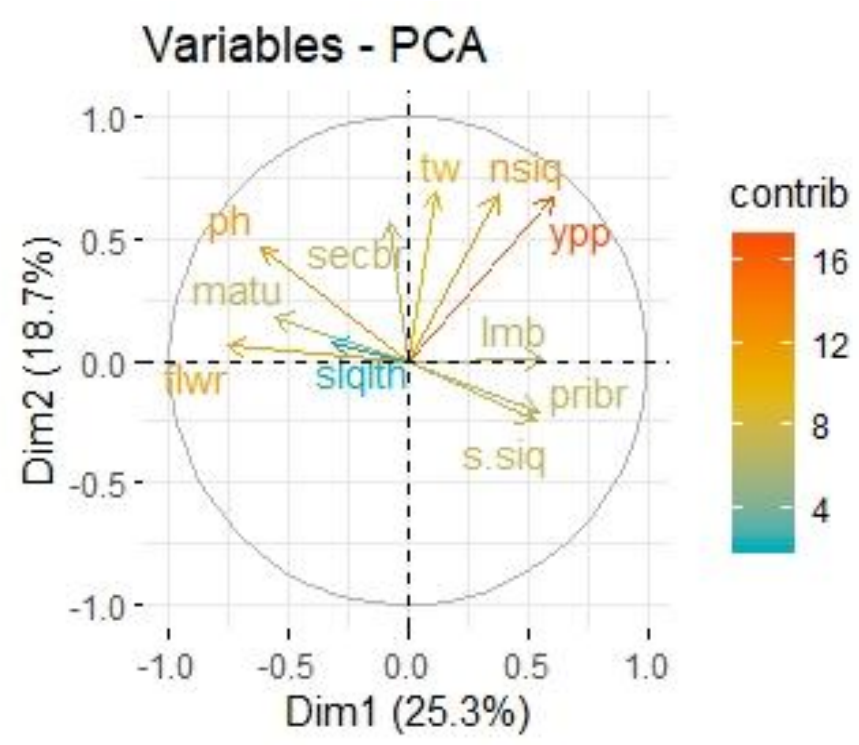

Figure.1 Plot of Principal component analysis (PCA) of different variables showing their contribution towards total variation

Occurrence of both positive and negative loading in a single component shows the presence of positive and negative correlation trends between the components and the variables. All the characters except number of secondary branches per plant and number of seeds per silique were contributed positively to the second principal component (PC2) accounting for 18.71 per cent of the variability explained.

The third component accounts for 13.63 per cent of total variability and the characters viz., days to $50 \%$ flowering, length of siliqua, number of seeds per silique, 1000 seed weight and seed yield per plant contributed in positive way. The fourth component had positive loadings for all the characters except number of secondary branches per plant, length of main branch, length of silique and 1000 seed weight accounting for 8.91 per cent of the total variability.

The fifth component had positive and high loadings for all the characters except days to maturity, number of seeds per silique, 1000 seed weight and seed yield per plant and contributed 8.30 per cent of the total variability. Pattern of relationships obtained through PCA are useful to evaluate potential breeding value of germplasm through traits loaded on various components. Factor loadings of eleven characters with respect to different PC's are shown in Table 2. Using PCA, it was possible to access the degree of divergence to understand the trend of their evolutionary pattern and to assess the relative contribution of different components to the total divergence.

The results are in agreement with various other studies that reported the maximum contribution of number of silique per plant, number of seeds per silique and 1000 seed weight towards genetic divergence in Indian mustard. These results were in accordance with the studies conducted by Naznin et al., 2015, Pankaj et al., 2017, Chandra et al., 2018 and Gupta et al., 2019. The prominent characters identified in a particular principal component as prime contributors to total variability have the tendency to perform together and can be used effectively for selection in crop breeding programmes. In all the five components traits like number of silique per plant, seed yield per plant and 
number of seeds per siliqua contributed positively to the total variation. Hence these traits can be used for selection in crop breeding programmes in Indian mustard.

\section{References}

Belete, Y.S., Kebede, S.A. and Gemelal, A. W. 2011. Multivariate analysis of genetic divergence among Ethiopian mustard (Brassica carinata A. Braun) genotypes in relation to seed oil quality traits. Int.J. Agri. Res., 6: 494 -503.

Chandra, K., Pandey, A. and Mishra, S. B. 2018. Principal component analysis of Indian mustard genotypes for morphophysiological traits under rainfed condition. Green Farming,9(3): 404408.

Gupta, M.C., Sharma, A. K., Singh, A. K., Roy, H. S. and Bhadauria, S. S. 2019. Assessment of Genetic Diversity in Thirty-Five Genotypes of Oilseed Brassica Species using Principal Component Analysis. Int.J.Curr.Microbiol.App.Sci., $\quad$ 8(1): 378-386.

Mohan, S., Yadav, R. K., Tomar, A. and Singh, M. 2017. Genetic divergence analysis in Indian mustard (Brassica juncea (L.) Czern\&Coss). J. of
Pharmacognosy and Phytochemistry, 6(1): 350-351.

Nagaharu, U. 1935. "Genome analysis in Brassica with special reference to the experimental formation of $B$. napus and peculiar mode of fertilization". Japan. J. Bot., 7: 389452.

Naznin, S., Kawochar, M. A., Sultana, S., Zeba, N. and Bhuiyan, S. R. 2015. Genetic Divergence in Brassica rapa $\mathrm{L}$. Bang. J. Agric. Res.,40(3): 421-433.

Neeru, Thakral, N K., Avtar, R. and Singh, A 2015. Evaluation and classification of Indian mustard (Brassica juncea L.) genotypes using principal component analysis. J. Oilseed Brassica, 6 (1): 167-174.

Pankaj, R., Avtar, R., Kumari, N., Jattan, M., Rani, B., Manmohan and Sheoran, R. K. 2017. Multivariate analysis in Indian mustard genotypes for morphological and quality traits. Electronic J. Plant Breed., 8(2): 450-458.

Ray, K., Dutta, J., Banerjee, H., Biswas, R., Phonglosa, A. and Pari, A. 2014. Identification of principal yield attributing traits of Indian mustard [Brassica juncea (L.) Czern and Coss] using multivariate analysis. The Bioscan, 9(2): 803-809.

\section{How to cite this article:}

Neelam Shekhawat and Kartar Singh. 2020. Genetic Characterization of Indian mustard (Brassica juncea L.) Germplasm for Quantitative Traits through Principal Component Analysis. Int.J.Curr.Microbiol.App.Sci. 9(05): 1192-1196.

doi: https://doi.org/10.20546/ijcmas.2020.905.132 